\title{
Female Short Shoot and Ovule Development in Ginkgo biloba L. with Emphasis on Structures Associated with Wind Pollination
}

\author{
Biao Jin,, ${ }^{1}$ Di Wang, ${ }^{1}$ Yan Lu, ${ }^{1}$ Xiao Xue Jiang, ${ }^{1}$ Min Zhang, ${ }^{1}$ Lei Zhang, ${ }^{1}$ and Li Wang ${ }^{1,2}$ \\ ${ }^{1}$ College of Horticulture and Plant Protection, Yangzhou University, Yangzhou 225009, China \\ ${ }^{2}$ Key Laboratory of Plant Molecular Physiology, Institute of Botany, Chinese Academy of Sciences, Beijing 100093, China
}

Correspondence should be addressed to Li Wang, liwang@yzu.edu.cn

Received 31 May 2012; Accepted 17 July 2012

Academic Editors: C. Bolle, A. M. Rashotte, and S. Sawa

Copyright ( 2012 Biao Jin et al. This is an open access article distributed under the Creative Commons Attribution License, which permits unrestricted use, distribution, and reproduction in any medium, provided the original work is properly cited.

\begin{abstract}
The orientation and morphology of the female cone are important for wind pollination in gymnosperms. To examine the role of female reproductive structures associated with wind pollination in Ginkgo biloba, we used scanning electron microscopy and semithin section techniques to observe the development of female short shoots and ovules in G. biloba before and during the pollination period. The ovule differentiation process was divided into six stages: undifferentiated, general stalk differentiation, integument differentiation, nucellus differentiation, collar differentiation, and mature stage. Before the pollination period, the integument tip generated the micropylar canal and the micropyle, while the nucellus tip cells degenerated to form the pollen chamber. During pollination, the micropylar canal surface became smooth, the micropyle split into several pieces and bore a pollination drop, and the pollen chamber directly faced the straight micropylar canal. The leaves and ovules were spirally arranged on the female short shoot, with the ovules erect and the fan-shaped leaves bent outwards and downwards. The ovules of $G$. biloba have differentiated some special architectural features adapted for pollen capture and transport. Together, these structures constitute a reproductive structural unit that may improve wind pollination efficiency at the female level.
\end{abstract}

\section{Introduction}

Pollination is an important process in the life cycle of seed plants. During the evolution of angiosperms, diverse forms of pollination with complex mechanisms have evolved. Among the gymnosperm species, the majorities are wind pollinated (anemophilous) and their pollen grains are carried from their initial location to female parts via air flow [1]. Thus, wind pollination in gymnosperms is a random and inefficient process with high pollen losses. There have been many studies documenting how gymnosperms achieve pollination via such relatively passive processes. For example, the pollination process has been studied in several conifer families, such as the Podocarpaceae, Cupressaceae, Taxaceae, and Pinaceae, and the proposed evolution of different pollination mechanisms has been widely discussed [2-4]. Based on the results of such studies, it was concluded that adaptive characteristics to wind pollination that contribute to the pollination mechanisms of gymnosperms involve (1) orientation of the ovulate cone, as well as ovule structure and position at the time of pollination $[2,5] ;(2)$ pollen characteristics, especially the presence or absence of sacci $[6,7]$; (3) whether a pollination drop appears at pollination or not $[8,9]$. Among these characteristics, the ovule as the female reproductive organ varies widely in its morphology among gymnosperms. Studies on ovule development in gymnosperms have revealed various ovule structures that have evolved to increase the chances of pollination success. For instance, the tip of the integument in the ovule shows a variety of shapes for pollen collection. Owens et al. [2] reported that in the Cupressaceae, Taxodiaceae, and Cephalotaxaceae, the ovules are flask-shaped, variable in number, and attached in the axil of the bract scale, and the integument tip has a narrow neck and a small, unspecialized micropyle. However, in Abies species, the integument tip forms a short funnel, often with fluted edges, around a large micropyle [10]. In addition, the orientation and morphology of the megastrobilus (female cone) are important features for wind pollination. For example, in some conifer species, ovulate cones may enhance the probability of pollen entrapment 
by aerodynamically predetermining airflow patterns around scale-bract complexes [11]. Together, the results of such studies showed that the diverse morphologies and structures of female reproductive organs among gymnosperms are an evolutionary consequence of adaptation for effective pollen reception. Thus, it is important to study ovule development of gymnosperms to further clarify the roles of various ovule characteristics in the wind pollination mechanism.

Ginkgo biloba L. is the unique living species of the ancient lineage of Ginkgophyta, which originated in the Paleozoic Carboniferous period; thus, it is regarded as a "living fossil" [12]. The female reproductive organ of G. biloba, particularly the ovule, has been described and studied extensively because of several unique and primitive characteristics $[13,14]$. The ovule differentiates into the integument, nucellus, and collar [15]. Primarily, the integument develops in a circumferential manner and becomes slightly lobed during the formation of the micropyle [16]. After that, the nucellar tissues are derived from periclinal divisions in the hypodermal layer, and the tip cells of the nucellus die, resulting in formation of the pollen chamber [17]. Almost simultaneously, one cell in the sporangial tissues differentiates to form a spore mother cell, which further develops to form the female gametophyte, while the other cells differentiate to form the tapetum [18]. During the pollination period, the ovule produces a pollination drop $[19,20]$. Although these studies have described the ovule developmental process in G. biloba, most have focused on either the morphological structures or the floristic features. Since G. biloba is a wind-pollinated dioecious plant and this lineage has existed for more than 200 million years, the Ginkgo ovule is obviously a survivor of evolutionary consequences related to wind pollination. However, so far, there have been no systematic studies of how ovule structure has differentiated to adapt to wind pollination. Moreover, while previous studies have provided information about the formation of the female gametophyte, the developmental conditions of the female gametophyte before and during the pollination period remain unclear $[21,22]$. In addition, the erect ovules surrounding by several fan-shaped leaves constitute the overall female short shoot system, which clearly works as a whole during wind pollination. However, the specific spatial arrangement and architecture of the short shoot have received little attention, despite the fact that these are important features for comprehensively understanding the female reproductive system associated with wind pollination in G. biloba.

Based on our previous studies [21,23], in this paper we investigated the morphological and structural development of female short shoots and ovules in G. biloba, focusing on ontogenetic features and their relationships with pollen capture. We used continuous image acquisition, semithin sectioning, and SEM observation techniques to observe the morphological and anatomical changes. We present morphological data that clarify the relationships between female reproductive structures and wind pollination in $G$. biloba, providing further insights into the wind pollination mechanisms in gymnosperms.

\section{Materials and Methods}

2.1. Plant Material. Healthy female G. biloba L. trees were selected from the Ginkgo Experimental Station at Yangzhou University, Yangzhou, China $\left(32^{\circ} 20^{\prime} \mathrm{N}, 119^{\circ} 30^{\prime} \mathrm{E}\right)$. Ovules were collected weekly from August 2008 to April 2009. Between mid-March and early April, the period for female gametophyte and pollen chamber development, ovules were collected daily. Ovules in bud were dissected out using a razor blade and a steel needle, and the nucellus together with the pollen chamber was manually isolated from ovules under a dissecting microscope.

2.2. Digital Camera Observation Studies. Potential female buds were randomly sampled and tagged to follow their development. Photographs were taken against a black background each week from August 2008 to mid March 2009 using a DSC-H7 Sony digital camera. Between midMarch and late April 2009, female buds and ovules were photographed daily until pollination ended.

2.3. Semithin Section Studies. The material was prepared for semi-thin sectioning as follows: at each sampling, 30 fresh ovules were prefixed in $2.5 \%(\mathrm{v} / \mathrm{v})$ glutaraldehyde in $0.1 \mathrm{~mol} / \mathrm{L}$ phosphate buffer $(\mathrm{pH} 7.2)$ for $20 \mathrm{~h}$ at room temperature, postfixed in $1 \%(\mathrm{w} / \mathrm{v})$ osmium tetroxide for $6 \mathrm{~h}$ at $4^{\circ} \mathrm{C}$, rinsed twice, dehydrated in an alcohol series $(30,50$, $70,80,90,95$, and $100 \%, 15$ min each step), treated twice for 10 min with propylene oxide, infiltrated with $1: 1$ propylene oxide/resin in embedding capsules overnight, and then finally embedded in Spurr's resin. Semi-thin sections $(1 \mu \mathrm{m})$ were cut with an Leica EM UC6 ultramicrotome (Leica Microsystems GmbH, Wetzlar, Germany) and collected onto glass slides, then stained with $1 \%(\mathrm{w} / \mathrm{v})$ toluidine blue $\mathrm{O}$ dissolved in $1 \%(\mathrm{w} / \mathrm{v})$ sodium borate prior to examination [24]. Observations and photography were performed under a microscope (Zeiss Axioskop 40: Carl Zeiss Shanghai Company Ltd., Shanghai, China).

2.4. SEM Observation Studies. Samples were prepared for SEM observations as follows: at each developmental stage, 30 intact ovules were dissected from buds under a dissecting microscope. The samples were fixed in $2.5 \%$ glutaraldehyde (in $0.1 \mathrm{~mol} / \mathrm{L}$ phosphate buffer, $\mathrm{pH} 7.0$ ) for $4 \mathrm{~h}$ at room temperature and then kept for $12 \mathrm{~h}$ at $4^{\circ} \mathrm{C}$. Then, they were dehydrated in a graded ethanol series $(30,50,70,80$, 90, 95 and 100\%, 15 min each step). After drying at the critical point, the specimens were coated with gold using an EMITECH K550 sputter coater for 150 s, and observed under a Hitachi H-300 scanning electron microscope (Tokyo, Japan) at $15 \mathrm{kv}$ accelerating voltage [25].

\section{Results}

3.1. Female Cone Initiation and Sprouting Process. The female buds of $G$. biloba, borne at the apex of the shortshoots, were conical-shaped with the apex slightly acuminate and nearly enclosed by seven to nine thick-bud scales from September to the next February (Figure 1(a)). In late March, 


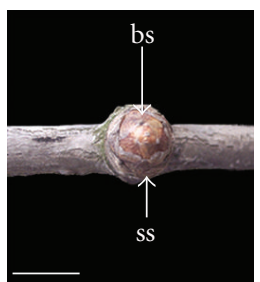

(a)

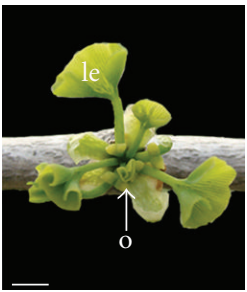

(g)

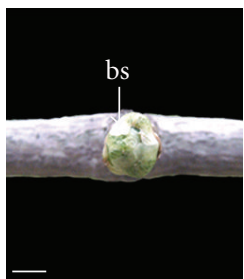

(b)

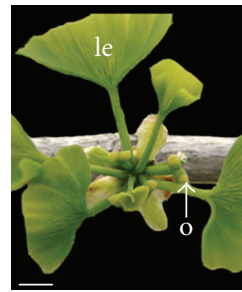

(h)

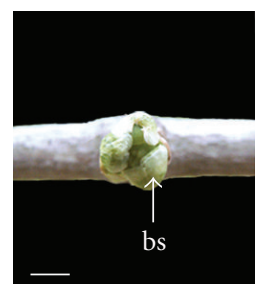

(c)

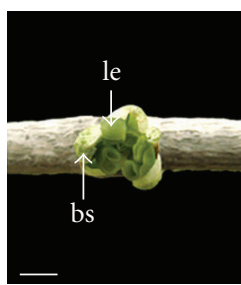

(d)

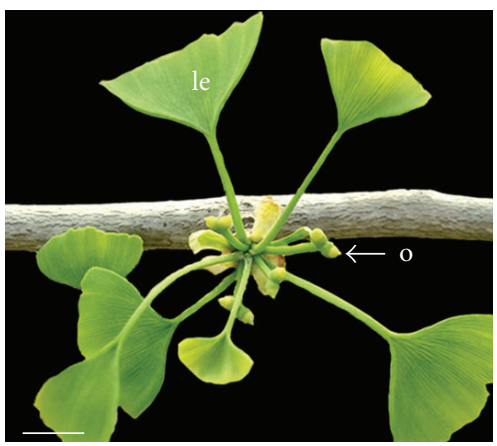

(i)

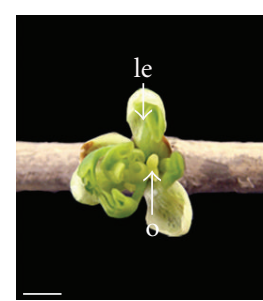

(e)

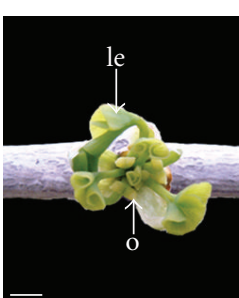

(f)

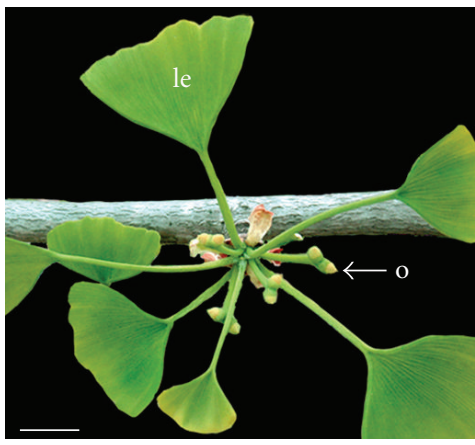

(j)

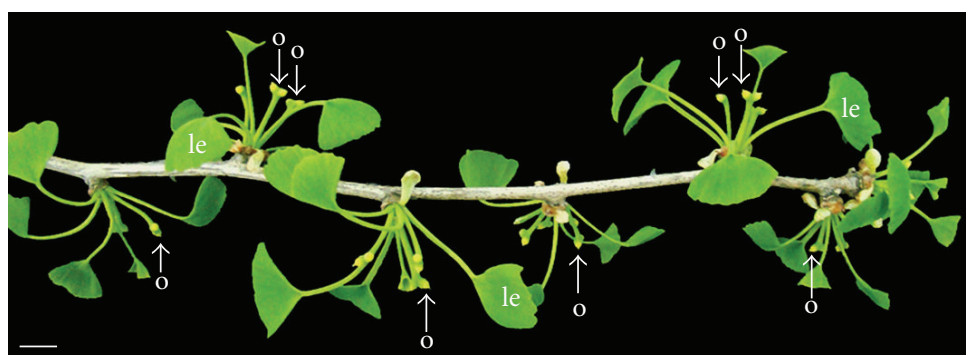

(k)

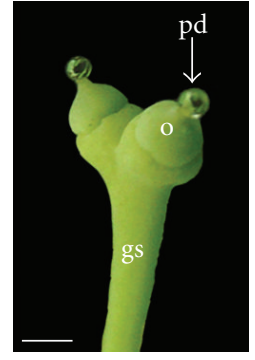

(l)

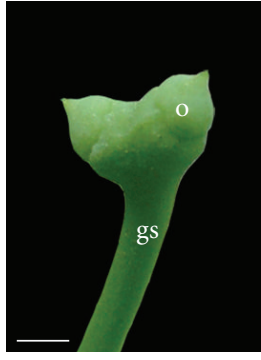

(m)

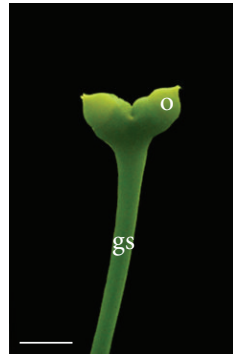

(n)

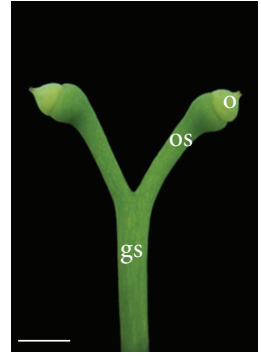

(o)

Figure 1: Female cone development of G. biloba. (a) Female cone enclosed by thick bud scales during winter. ((b)-(d)) Bud scales opened gradually in late March. (e) Ovules began to appear in early April. ((f)-(h)) Ovular stalks elongated and leaves grew rapidly. (i) Leaves and ovules spirally arranged on the short shoot apex just before pollination. (j) Leaves and ovules during pollination stage (mid-April). (k) Long shoot with several female short shoots during pollination. (l) Pollination drop secreted from micropyle. (m) Ovules changed from yellow to green after pollination. (n) Ovules attached directly to general stalk. (o) Ovule with ovular stalks. bs, bud scale; gs, general stalk; le, leaf; o, ovule; os, ovular stalk; pd, pollination drop; ss, short shoot. Bars: $((\mathrm{a})-(\mathrm{f}))=50 \mathrm{~mm} ;((\mathrm{i})-(\mathrm{k}))=1 \mathrm{~cm} ;((\mathrm{l})-(\mathrm{m}))=5 \mathrm{~mm} ;((\mathrm{n})-(\mathrm{o}))=2 \mathrm{~mm}$.

the bud scales began to unfold, and over several days, the outer brown scales opened to expose the inner green ones (Figure 1(b)). Continued unfolding of the bud scales resulted in the appearance of the leaves and ovules (Figures $1(\mathrm{c})-1(\mathrm{e}))$. Most of the ovules were concealed in the bud because both the leaf stalks and ovular stalks were very short. At this stage, the leaves were young and curved inward from the two lateral sides (Figures 1(d) and 1(e)). As the leaves developed, all of the ovules in the buds became visible (Figures $1(\mathrm{f})$ and $1(\mathrm{~g})$ ). At this stage, the ovules were yellow. Afterwards, the leaves began to spread gradually and the leaf stalks rapidly elongated. At the same time, the ovular stalks began to extend rapidly, pushing the ovules outward from the bud (Figure $1(\mathrm{~h})$ ). This resulted in a spiral arrangement of the ovules and leaf tufts on the female short shoot. The fan-shaped leaves spread out and bent 


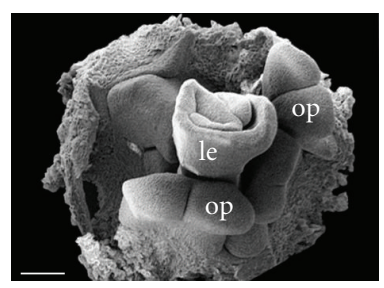

(a)

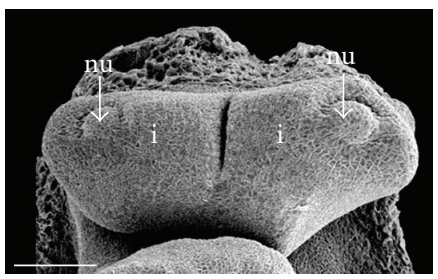

(e)

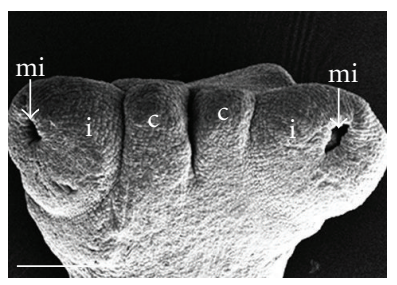

(i)

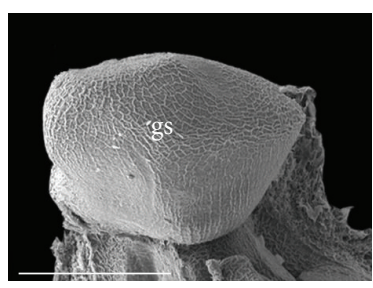

(b)

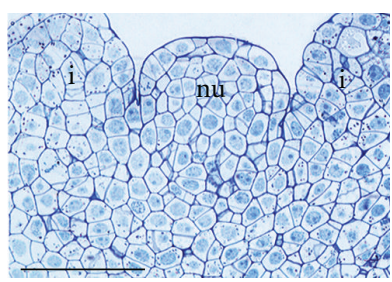

(f)

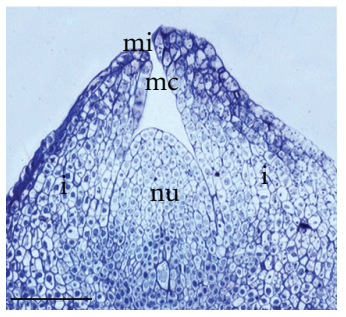

(j)

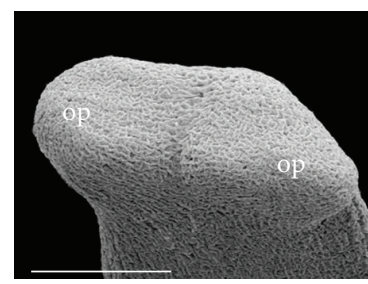

(c)

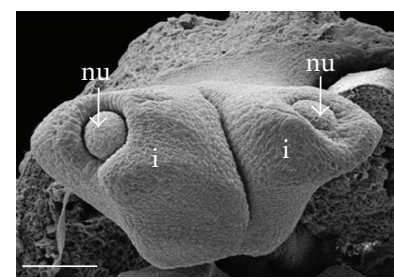

(g)

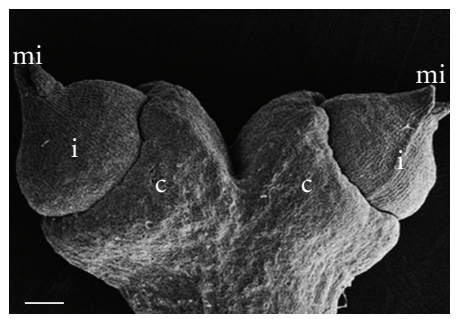

(k)

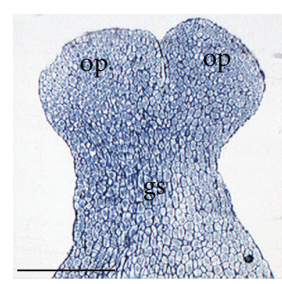

(d)

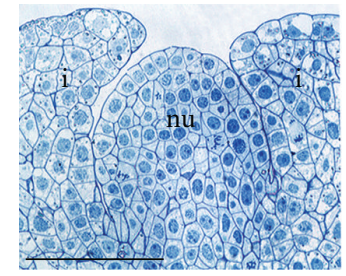

(h)

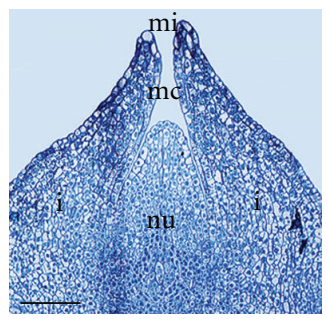

(1)

Figure 2: Tissues during ovule differentiation process in G. biloba. (a) Position of ovules and leaf in female bud. (b) General stalk differentiated and its tip extended and swelled. ((c)-(d)) Formation of integument primordium on tip general stalk. ((e)-(f)) Center of integument differentiated into nucellar tissue. ((g)-(j)) Integument tissue grew to encircle nucellus. ((k)-(l)) Mature ovules with welldeveloped collar, integument, nucellus, micropyle, and micropyle tunnel. co, collar; gs, general stalk; i, integument; le, leaf; mi, micropyle;

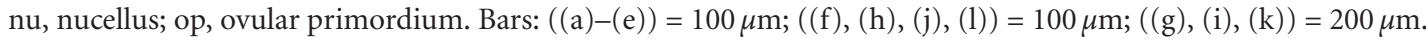

outwards and downwards (Figure 1(i)). During this period, the ovules were still yellow, erect, and inclined obliquely at various angles. During the pollination period, in midApril, almost all of the female short shoots were open with several ovules in the center (Figures $1(\mathrm{j})$ and $1(\mathrm{k})$ ), and each ovule produced a pollination drop on the micropyle (Figure 1(1)). After pollination, the color of ovules changed from yellow to green as the pollination drop disappeared (Figure $1(\mathrm{~m})$ ). Usually, a single general stalk bore two ovules that were directly attached to the stalk via ovular collars (Figure 1(n)). However, the general stalk of ovules occasionally differentiated into dichotomous separated stalks (ovule stalk), which connected the two ovular collars with the general stalk (Figure 1(o)).

3.2. Differentiation of Ovule Tissues. The ovule differentiation process was observed using scanning electron microscopy (SEM) and semi-thin sections. Our materials collected from Yangzhou in January 2009 had ovules in the early stage of development (Figure 2(a)), although we did not know the exact time of ovule initiation (maybe in December or earlier). The general stalk primordia of ovules were initiated at and around the boundary between bud scales and leaves in the first year, and they remained in this stage for a long time (about 1 month). Until the next
January, the tip of the general stalk was swollen, giving the stalk an ellipse-like appearance (Figure 2(b)). Afterwards, the swollen primordium stretched on both lateral sides to differentiate into the integument primordium (Figure 2(c)). The cells of the integument primordium were very small and tightly arranged, and the nuclei could not be distinguished easily (Figure 2(d)). The integument tissues showed active cell division, in contrast to the center part of the general stalk. The cell division between the integument tissues led to the formation of a dorsal raphe between them (Figures $2(\mathrm{c})$ and $2(\mathrm{~d})$ ). Further differentiation became visible in mid-March. As the integument developed rapidly, the dorsal raphe developed further, causing the integument to separate into two independent parts. Then, the nucellus was initiated on the convex region of each integument, forming a faint ridge (Figure 2(e)). At this stage, the nucellar tissue was rounded with a flat tip, and its cells were similar in size and appearance to those in the integument (Figure 2(f)). Afterwards, the nucellus continued to differentiate and became free from the integument, causing the latter to show a cup-like shape (Figure 2(g)). Then, rapid cell division resulted in rapid growth of the integument, which grew bigger than, and eventually engulfed, the nucellus (Figure 2(h)). The integument completely surrounded the nucellus in late March (Figure 2(i)). Meanwhile, the ovule 
collar differentiated from cells between the base of the integument and the top of the ovular stalk (Figure 2(i)). After that, the integument proceeded to differentiate upwards, instead of ceasing growth, giving rise to the micropyle and micropylar canal (Figure $2(\mathrm{j})$ ). The mature ovule had a welldefined integument and ovular collar (Figure 2(k)). The micropyle was situated on the opposite side of the collar, and the column-like nucellus was in the center of the integument (Figure 2(1)).

\subsection{Formation of Pollen Capturing and Transporting Tis-} sues. In G. biloba, the pollen capturing and transporting tissues include the micropyle, micropylar canal, and pollen chamber. Among them, the micropyle and micropylar canal are formed by the integument, while the pollen chamber is formed by the tip of the nucellus. In about mid-March, after the nucellus had differentiated from the center of the integument primordium, it continued to grow upwards by rapid cell division (Figure 3(a)). Because of the more frequent cell divisions of the integument, the nucellus was gradually engulfed by the surrounding integument (Figure $3(\mathrm{~b}))$. When the nucellus was buried deeply in the ovule, the tip of the integument fused toward the very center at the top of the nucellus (Figure 3(c)). Then, the nucellus ceased to extend and became completely concealed by the integument (Figure 3(d)), while the latter continued to grow upwards (Figures 3(e)-3(h)). Therefore, the integument encircled the top of the nucellus to emerge as the micropyle (Figure 3(i)). Some of the cells under the micropyle formed a tunnellike structure, the micropylar canal (Figure 3(j)). During its differentiation process, the micropyle showed a wavy shape, rather than a ring-shape (Figures 3(f)-3(i)). This was probably because of the differential growth rate of different regions of the upper integument. The micropylar canal cells were almost rectangular and had smooth surfaces (Figures $3(\mathrm{k})$ and $3(\mathrm{k}-1))$. As the micropyle and micropylar canal further developed, the nucellus became column-shaped (Figure 3(1)) and slightly acute on the tip side (Figures $3(\mathrm{~m})$ and $3(\mathrm{n}))$. Some cells near the micropyle elongated longitudinally and collapsed (Figure 2(1)), resulting in a cavity (the pollen chamber) at the nucellus tip (Figures 3(o) and $3(\mathrm{p}))$. During the pollination period, all tissues were specialized for pollen capture and transport. The micropyle slightly curled outwards to form a funnel-like shape, and had a diameter of approximately $200 \mu \mathrm{m}$ (Figures 3(q) and $3(\mathrm{r}))$. The micropylar canal was straight and smooth, and was approximately $100 \mu \mathrm{m}$ wide and $500 \mu \mathrm{m}$ long (Figures $3(\mathrm{k})$ and $3(\mathrm{q}))$. The pollen chamber was well developed with its orifice directly oriented towards the micropyle and micropylar canal, and the diameter was approximately $100 \mu \mathrm{m}$ (Figures 3(p) and 3(r)).

3.4. Formation of the Female Gametophyte. After the micropyle was enclosed by the integument in late March (Figure $2(\mathrm{j})$ ), the megasporocyte (megaspore mother cell) initiated from the center of the nucellus, and was tightly surrounded by spongy tissue. The megasporocyte was very large relative to surrounding cells with a central nucleus (Figure 4(a)). In early April, when the tip of the nucellus began to degenerate to form the pollen chamber, the megasporocyte underwent meiosis. It divided along the longitudinal axis of the ovule, giving rise to the two cells of the dyad (Figure 4(b)). Upon formation of the dyad, the two cells immediately divided again to yield the linear tetrad of megaspores (Figure 4(c)). Among all the megaspores, the one near the chalazal end was typically the largest. The other three near the micropylar end were relatively small, and degenerated soon after (Figure 4(c)). Therefore, the chalazal megaspore enlarged and developed into the functional megaspore (Figure 4(d)). During the pollination period, when the pollen chamber reached its largest volume, the nucleus of the functional megaspore began to undergo series of karyokinetic divisions, forming many free nuclei (Figures $4(\mathrm{e})$ and $4(\mathrm{~g})$ ), indicating the beginning of the female gametophyte phase. At this stage, the surrounding spongy tissue was distinguishable from other cells as they contained vacuoles (Figure 4(f)).

\section{Discussion}

4.1. Differential Stages of the G. biloba Ovule. The structure of the mature $G$. biloba ovule is similar to that of many other gymnosperms. The mature ovule has a general stalk bearing two ovules at its tip, a single integument with the micropyle positioned opposite the stalk, some pollen grains in the pollen chamber, and many free nuclei [26]. However, some of the developmental stages of the ovule between initiation and maturation remained unclear. In our study, we observed the ovule differentiation process in $G$. biloba and divided it into six stages: (1) undifferentiated stage (from July to November), the leaf primordium had differentiated, but the ovule primordium was not visible; (2) general stalk differentiation stage (in December), the general stalk primordium appeared in axils of leaves and/or bracts; (3) integument differentiation stage (from January to early March), the tip of the general stalk was extended and swollen (Figure 2(b)), and later, the shoulder of the tip protruded upwards to form the integument primordium (Figures 2(c) and 2(d)), whose upper end then developed into the micropyle and the micropylar canal; (4) nucellus differentiation stage (from mid-March to early April), the nucellus differentiated from the center of the integument (Figure 2(e)); (5) collar differentiation stage (in late March), the ovulate collar differentiated quickly at the base of the integument (Figure 2(i)); and (6) mature stage (in midApril), a pollination drop appeared on each micropyle (Figure 1(1)), signaling that the ovule was well prepared, morphologically and structurally, for pollen entrapment. The nucellus differentiation stage was the key stage in ovule development, because the nucellus gives rise to the pollen chamber, and later, the female gametophyte.

4.2. Functions of Leaves during Pollination. Many plant lineages show a fossil history of consolidating individual reproductive organs into compound structures with emergent aerodynamic properties [26]. This appears to have increased the probability of pollination of the reproductive units. For example, wind-pollinated plants tend to show 


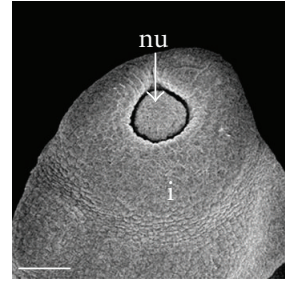

(a)

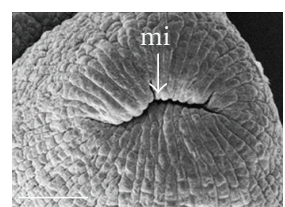

(e)

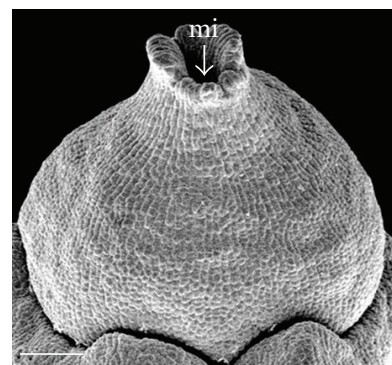

(i)

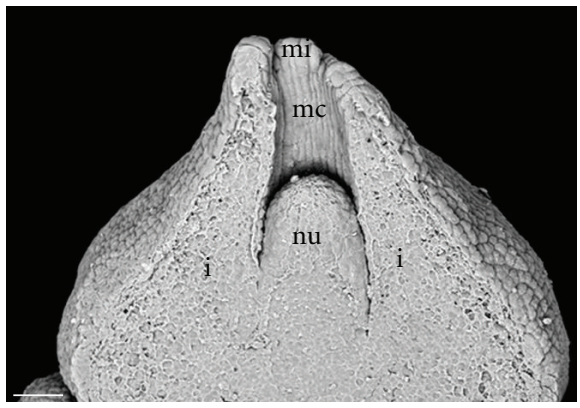

(1)

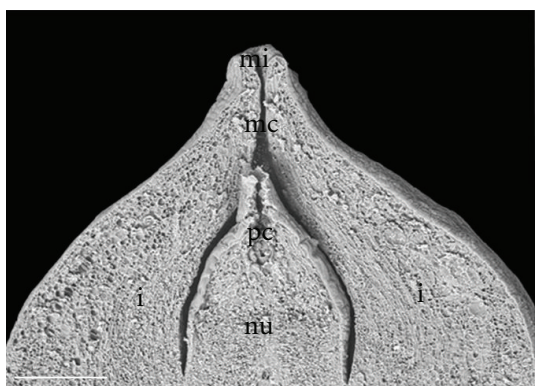

(q)

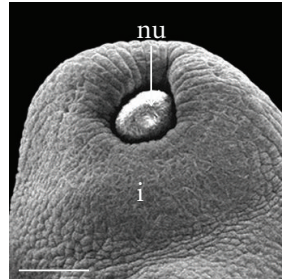

(b)

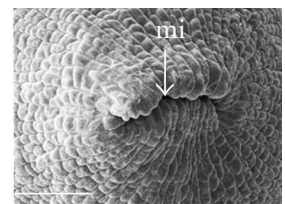

(f)

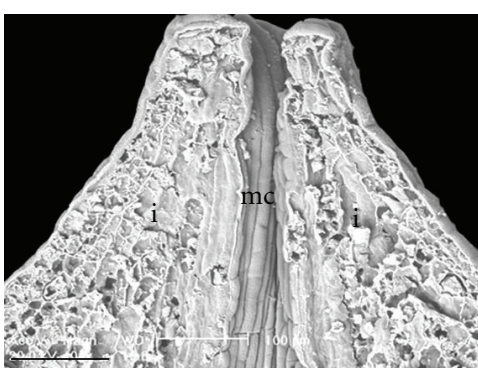

(j)

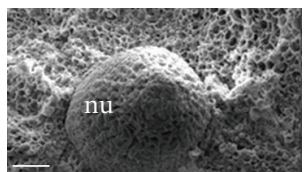

(m)

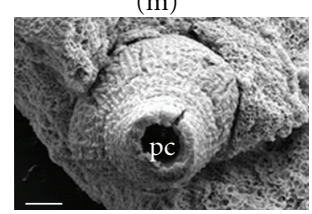

(o)

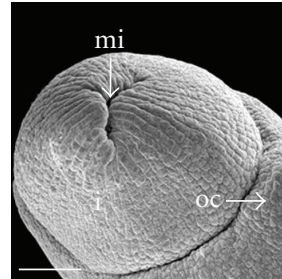

(d)

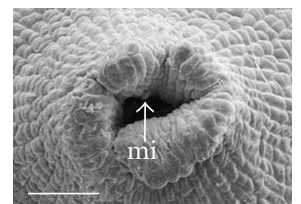

(h)

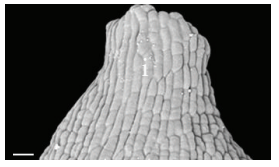

(k)

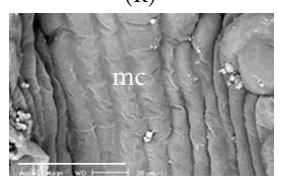

(k-1)

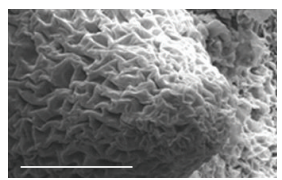

(n)

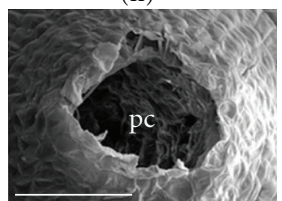

(p)

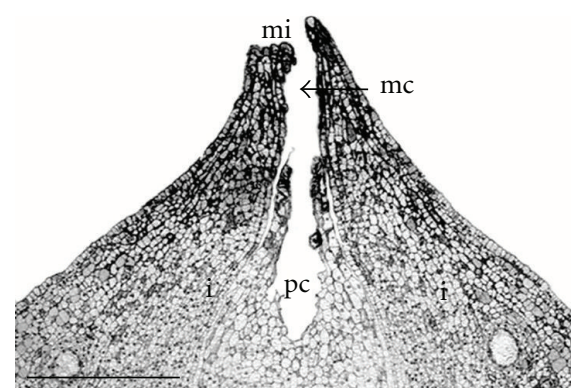

(r)

Figure 3: Development of tissues for pollen capture and transport in G. biloba. ((a)-(b)) After nucellus differentiation, integument continued to grow upward, surrounding nucellus. ((c)-(d)) Tip of integument gradually fused toward the center on top of nucellus. ((e)-(h)) Tip of integument continued growing upwards. (i) Formation of micropyle. (j) Micropylar canal. ((k), (k-1)) Cells of micropylar canal with smooth surfaces. (1) Column-shaped nucellus and developing micropylar canal. ((m)-(n)) Tip of nucellus became slightly acute. ((o)-(p)) Emergence of pollen chamber. ((q)-(r)) Ovules during pollination period with well-developed micropyle, micropylar canal, and pollen chamber. i, integument; mi, micropyle; mc, micropylar canal; nu, nucellus; oc, ovular collar; pc, pollen chamber. Bars: $((\mathrm{a})-(\mathrm{j}),(\mathrm{l})-(\mathrm{p}))=$ $100 \mu \mathrm{m} ;(\mathrm{k})=50 \mu \mathrm{m} ;((\mathrm{q})-(\mathrm{r}))=500 \mu \mathrm{m}$. 


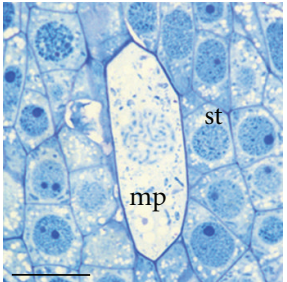

(a)

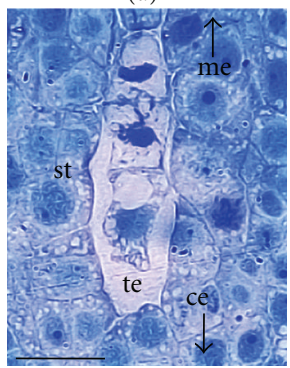

(c)

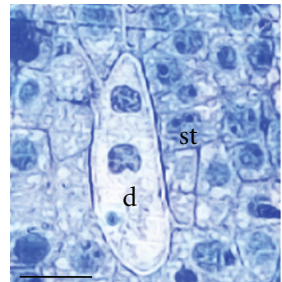

(b)

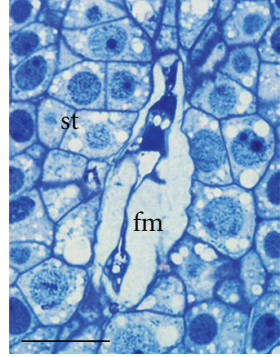

(d)

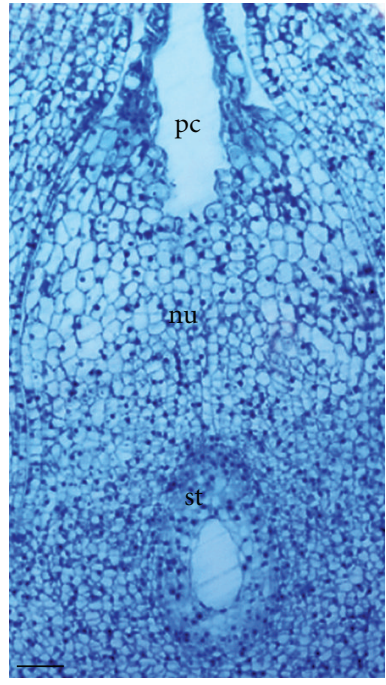

(e)

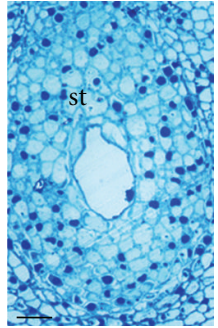

(f)

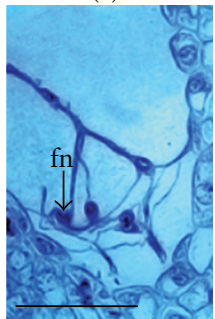

(g)

FIgURE 4: Formation of female gametophyte in G. biloba. (a) Megasporocyte differentiated from inner nucellar tissue in late March. (b) Dyad. (c) Tetrad. (d) Functional megaspore. ((e)-(g)) Approaching pollination stage, pollen chamber formed at apex of nucellus, and free nuclear stage of female gametocyte occurred. ce, chalazal end; $d$, dyad; fm, functional megaspore; fn, free nucleus; me, micropylar end; mp, megasporocyte; nu, nucellus; pc, pollen chamber; st, spongy tissue; te, tetrad. Bars: ((a)-(d), (g)) = 50 $\mu \mathrm{m} ;((\mathrm{e})-(\mathrm{f}))=100 \mu \mathrm{m}$.

a reduction in the size of branches, leaves, and other structures surrounding pollen-receptive spaces that could catch pollen grains, thereby reducing the ultimate number of pollen grains reaching receptive surfaces [27]. Moreover, the reduction in the size of these structures has been associated with modification of air currents towards receptive surfaces [27]. In addition, in some, but not all species of pine, leaf fascicles emerge around ovulate cones before pollination. As a result, pollen capture by the cone involves the aerodynamics of subtending leaf clusters [28]. In our study, we examined the development of the female short shoot and the orientation of leaves and ovules of G. biloba during pollination. We found before the bud scales unfolded, and ovules and leaves were borne at the apex of the short shoots and were surrounded by thick bud scales (Figure 1(a)). The ovules began to appear as the bud scales and leaves continued to unfold (Figures 1(b)-1(h)). Eventually, all scales, leaves, and ovules formed a spiral arrangement on the short shoot. The ovules were upright, and closer to the vertical axis of the shoot, while the leaves were fan-shaped, and extended further from the center, bending outwards and downwards (Figure 1(i)). Considering this architecture of the leaves and ovules during pollination, we supposed that the shapes and angles of leaves of G. biloba changed the aerodynamics around the ovule, which could increase the probability of pollen capture by the ovule. However, further experiments are required to determine whether or not the leaves of the female short shoot in $G$. biloba can produce favorable aerodynamics for pollen deposition.

4.3. The Ovulate Stalk. The general evolutionary trends of ovules in G. biloba include a reduction in the number of ovules, an increase in ovule size [29], and shortening or disappearance of the ovulate stalk [17]. Zhou [30] insisted that under the k-strategy, to balance weight and sustainability, the ovulate stalk became shorter, and then ultimately disappeared. Indeed, the single living species of Ginkgo has no ovulate stalk between the collar and general stalk. However, in our study, we found a low frequency of ovulate stalks that had differentiated on the top of the general stalk (Figure 1(o)). Considering that this phenomenon appeared more frequently in Ginkgo fossils [31], we believe the emergence of the ovulate stalk in living Ginkgo might reflect the vestigial expression of an underlying ancestral trait. From the view of the spatial arrangement of the ovules and leaves, the ovulate stalk represents advantageous architecture for ovules to trap pollen grains from the air. However, on the other hand, a long stalk also increases the risk of the pollination drop falling from the micropyle as a result of wind action during the pollination period. In addition, it is unfavorable to have a long developmental period after pollination, owing to the longer distance for nutrient transport and the increased energy demands of ovule bearing. These factors may have contributed to the disappearance of the furcated ovulate stalk during long-term evolution.

\subsection{Ovule Morphology and Structures Associated with Wind Pollination. Ovule orientation and morphology are vital features for wind pollination in gymnosperms. Traditionally, wind pollination is viewed as a simple matter of "chance," a mode of reproduction dominated by stochastic processes that predominate in the biology of long-distance dispersal [28]. However, a certain number of morphological features of reproductive units have evolved in divergent land plants that may contribute to the success of wind pollination [7]. For instance, female reproductive organs of gymnosperms showed considerable developmental flexibility, which would significantly influence the behavior of pollen grains in the air}


around the ovulate cones [11]. Furthermore, ovule geometry and position in relation to floral parts seem to play an essential role in affecting pollination efficiency [28]. In our study, we observed the G. biloba female cone and ovule structure and found many morphological and structural characteristics adapted to wind pollination. First, different from conifers in which ovules are often engulfed by other structures, such as bracts in Pinus monticola or lobes in Cunninghamia $[3,32]$, the organization of ovulate structures in $G$. biloba is very simple: the erect ovule is fully naked and is not enclosed by seed scales (Figure 1(j)). In addition, there is no distinctly organized lobe surrounding the ovule; this reduces boundary layer effects near ovules and increases the pollen-scavenging area (Figure $2(\mathrm{k})$ ). Therefore, during pollination, the micropyle orifice enlarges and forms a funnel-like shape, and a pollination drop is produced on the micropyle (Figures $1(1)$ and $3(q)$ ). It is interesting that the integument tip of the ovule, which includes the micropyle, does not emerge as strictly ring-shaped, but splits to several pieces (Figures 3(i) and 3(p)). Therefore, we propose that the architecture of the micropyle in G. biloba is adapted to produce a pollination drop with its size optimized for attachment of pollen grains, similar to other modifications of the integument tip in some conifers [3, 33-35]. Also, these adaptations could increase the contact area between the ovule and the pollination drop, decreasing the possibility of the pollination drop falling from the micropyle owing to the unexpected motion of the long shoot. Third, before pollination, the ovule differentiates into tissues adapted for pollen transport, including the micropyle, the micropylar canal, and the pollen chamber, of which the micropylar canal is straight and the cells on the inner surface are smooth (Figures $3(\mathrm{j})$ and $3(\mathrm{k})$ ). The pollen chamber is welldeveloped, and the orifice reaches its largest size as it faces the micropylar canal (Figure 3(r)). Thus, we assume that, at this moment, the structure of the ovule enables it to transport and accept pollen grains, and facilitates the movement of the pollen from the pollination drop to the pollen chamber.

4.5. Ovule Developmental State during Pollination. At the time of pollination, the developmental state of ovules varies among species, owing to wide variations in the period between pollination and fertilization, or the progamic phase [36]. Ordinarily, the angiosperm ovule, which contains an egg cell, two synergids, and a binucleated central cell at the micropylar pole, is already present during the pollination period, because angiosperms often have a relatively short progamic phase [37-39]. In contrast, since the time interval from pollination to fertilization varies among families, the ovules of gymnosperms have a variable developmental state at the time of pollination. For instance, pollination in Podocarpus totara [40] and Larix decidua [41] occurred when the functional megaspore inside the ovule developed and became the mother cell of the female gametophyte, whereas the female gametophyte of interior spruce was cellular at pollination [42]. In the present study, the female gametophyte of the G. biloba ovule was in the free nuclei stage (Figures $4(\mathrm{e})$ and $4(\mathrm{~g}))$ during the pollination period. According to Wang et al. [22], there were approximately $130 \mathrm{~d}$ between the initiation of karyomitosis in the female gametophyte and the formation of the mature archegonium. Meanwhile, there were also approximately $130 \mathrm{~d}$ between entry of the pollen grain into the pollen chamber at the time of pollination and development of the male gametophyte into the mature spermatozoid at the time of fertilization. Thus, we can conclude that the female gametophyte phase occurring inside the ovule during the pollination period might be in preparation for fertilization at the later period. Therefore, the developmental processes of the male and female gametophyte are coordinated after pollination, thereby ensuring that the male and female gametes meet at the correct developmental stage during the short fertilization period.

\section{Author's Contribution}

D. Wang and Y. Lu contributed equally to this work.

\section{Acknowledgments}

The authors thank Prof. Peng Chen and Prof. Zhong Wang of Yangzhou University, China, for technical advice. This work was supported by the Natural Science Fund of Jiangsu Province (no. BK2011444), Science and Technology Innovation Fund of Xuzhou City (no. XF11C001), and the National Natural Science Foundation of China (no. 30870436).

\section{References}

[1] M. Proctor, P. Yeo, and A. Lack, The Natural History of Pollination, Timber Press, Portland, Ore, USA, 1996.

[2] J. N. Owens, T. Takaso, and C. John Runions, "Pollination in conifers," Trends in Plant Science, vol. 3, no. 12, pp. 479-485, 1998.

[3] J. N. Owens, G. Catalano, and J. S. Bennett, "The pollination mechanism of western white pine," Canadian Journal of Forest Research, vol. 31, no. 10, pp. 1731-1741, 2001.

[4] L. M. Chandler and J. N. Owens, "The pollination mechanism of Abies amabilis," Canadian Journal of Forest Research, vol. 34, no. 5, pp. 1071-1080, 2004.

[5] C. J. Runions, K. H. Rensing, T. Takaso, and J. N. Owens, "Pollination of Picea orientalis (Pinaceae): saccus morphology governs pollen buoyancy," American Journal of Botany, vol. 86, no. 2, pp. 190-197, 1999.

[6] A. B. Schwendemann, G. Wang, M. L. Mertz, R. T. McWilliams, S. L. Thatcher, and J. M. Osborn, "Aerodynamics of saccate pollen and its implications for wind pollination," American Journal of Botany, vol. 94, no. 8, pp. 1371-1381, 2007.

[7] Y. Lu, B. Jin, L. Wang et al., "Adaptation of male reproductive structures to wind pollination in gymnosperms: cones and pollen grains," Canadian Journal of Plant Science, vol. 91, no. 5, pp. 897-906, 2011.

[8] G. Gelbart and P. Von Aderkas, "Ovular secretions as part of pollination mechanisms in conifers," Annals of Forest Science, vol. 59, no. 4, pp. 345-357, 2002.

[9] S. Mugnaini, M. Nepi, M. Guarnieri, B. Piotto, and E. Pacini, "Pollination drop in Juniperus communis: response to deposited material," Annals of Botany, vol. 100, no. 7, pp. 1475-1481, 2007. 
[10] H. Singh and J. N. Owens, "Sexual reproduction in grand fir (Abies grandis)," Canadian Journal of Botany, vol. 60, no. 11, pp. 2197-2214, 1982.

[11] K. J. Niklas and K. T. P. U, "Pollination and airflow patterns around conifer ovulate cones," Science, vol. 217, no. 4558, pp. 442-444, 1982.

[12] L. Wang, D. Wang, M.-M. Lin, Y. Lu, X.-X. Jiang, and B. Jin, "An embryological study and systematic significance of the primitive gymnosperm Ginkgo biloba," Journal of Systematics and Evolution, vol. 49, no. 4, pp. 353-361, 2011.

[13] M. Favre-Duchatre, "Ginkgo, an oviparous plant," Phytomorphology, vol. 8, pp. 377-396, 1958.

[14] Z. L. Lee, "Recent advances (1949-1959) in morphology, anatomy and cytology of Ginkgo Biloba L," Acta Botanica Sinica, vol. 8, no. 4, pp. 262-270.

[15] A. W. Douglas, D. W. Stevenson, and D. P. Little, "Ovule development in Ginkgo biloba L., with emphasis on the collar and nucellus," International Journal of Plant Sciences, vol. 168, no. 9, pp. 1207-1236, 2007.

[16] L. Wang, Y. P. Wang, Q. Wang et al., "Anatomical study of development of ovule in Ginkgo biloba L," Acta Botanica Boreali-Occidentalia Sinica, vol. 27, no. 7, pp. 1349-1356, 2007.

[17] D. H. Li, X. Yang, X. Cui, K. M. Cui, Z. L. Li, and C. L. Lee, "Early development of pollen chamber in Ginkgo biloba Ovule," Acta Botanica Sinica, vol. 44, no. 7, pp. 757-763, 2002.

[18] C. J. Ji, X. Yang, and Z. L. Li, "Morphological studies on megaspore formation in Ginkgo biloba," Acta Botanica Sinica, vol. 41, no. 7, pp. 219-221, 1999.

[19] W. E. Friedman, "Growth and development of the male gametophyte of Ginkgo biloba within the ovule (in Vivo)," American Journal of Botany, vol. 74, no. 12, pp. 1797-1815.

[20] B. Jin, L. Zhang, Y. Lu et al., "The mechanism of pollination drop withdrawal in Ginkgo biloba L," BMC Plant Biology, vol. 12 , no. 59, 2012.

[21] L. Wang, B. Jin, M. M. Lin, Y. Lu, N. J. Teng, and P. Chen, "Studies of the development of female reproductive organs in Ginkgo biloba L," Chinese Bulletin of Botany, vol. 44, no. 6, pp. 673-681, 2009.

[22] L. Wang, Y. Lu, B. Jin, M. M. Lin, and P. Chen, "Gametophyte development and embryogenesis in Ginkgo biloba: a current view," Chinese Bulletin of Botany, vol. 45, no. 1, pp. 119-127, 2010.

[23] L. Wang, B. Jin, Y. Lu, X. X. Jin, N. J. Teng, and P. Chen, "Developmental characteristics of the ovule and its biological significance in Ginkgo biloba L," Journal of Beijing Forestry University, vol. 32, no. 2, pp. 79-85, 2010.

[24] B. Jin, L. Wang, J. Wang et al., "The effect of experimental warming on leaf functional traits, leaf structure and leaf biochemistry in Arabidopsis thaliana," BMC Plant Biology, vol. 11, article 35, 2011.

[25] B. Jin, L. Wang, J. Wang et al., "The structure and roles of sterile flowers in Viburnum macrocephalum f. keteleeri (Adoxaceae)," Plant Biology, vol. 12, no. 6, pp. 853-862, 2010.

[26] M. W. Frohlich and M. W. Chase, "After a dozen years of progress the origin of angiosperms is still a great mystery," Nature, vol. 450, no. 7173, pp. 1184-1189, 2007.

[27] K. J. Niklas, "Wind pollination-a study in controlled chaos," American Scientist, vol. 73, no. 5, pp. 462-470, 1985.

[28] K. J. Niklas, "The aerodynamics of wind pollination," The Botanical Review, vol. 51, no. 3, pp. 328-386, 1985.

[29] S. Zheng and Z. Zhou, "A new Mesozoic Ginkgo from western Liaoning, China and its evolutionary significance," Review of
Palaeobotany and Palynology, vol. 131, no. 1-2, pp. 91-103, 2004.

[30] Z. Y. Zhou, "Heterochronic origin of Ginkgo biloba-type organs," Acta Palaeontologica Sinica, vol. 33, no. 2, pp. 131139, 1994.

[31] Z. Y. Zhou, "An overview of fossil Ginkgoales," Palaeoworld, vol. 18, no. 1, pp. 1-22, 2009.

[32] A. Farjon and S. O. Garcia, "Cone and ovule development in Cunninghamia and Taiwania (Cupressaceae sensu lato) and its significance for conifer evolution," American Journal of Botany, vol. 90, no. 1, pp. 8-16, 2003.

[33] J. R. McWilliam, "The role of the micropyle in the pollination of Pinus," Botanical Gazette, vol. 120, no. 2, pp. 109-117, 1995.

[34] J. N. Owens, S. J. Simpson, and M. Molder, "The pollination mechanism and the optimal time of pollination in Douglas-fir (Pseudotsuga menziesii)," Canadian Journal of Forest Research, vol. 11, no. 1, pp. 36-50, 1981.

[35] J. N. Owens, S. J. Simpson, and G. Caron, "The pollination mechanism of Engelmann spruce (Picea engelmannii Parry)," Canadian Journal of Botany, vol. 65, no. 7, pp. 1439-1450, 1987.

[36] J. H. Williams, "Novelties of the flowering plant pollen tube underlie diversification of a key life history stage," Proceedings of the National Academy of Sciences of the United States of America, vol. 105, no. 32, pp. 11259-11263, 2008.

[37] W. E. Friedman and K. C. Ryerson, "Reconstructing the ancestral female gametophyte of angiosperms: insights from Amborella and other ancient lineages of flowering plants," American Journal of Botany, vol. 96, no. 1, pp. 129-143, 2009.

[38] V. Olmedo-Monfil, N. Durán-Figueroa, M. Arteaga-Vázquez et al., "Control of female gamete formation by a small RNA pathway in Arabidopsis," Nature, vol. 464, no. 7288, pp. 628$632,2010$.

[39] A. Cisneros, R. Benega Garcia, and N. Tel-Zur, "Ovule morphology, embryogenesis and seed development in three Hylocereus species (Cactaceae)," Flora, vol. 206, pp. 10761084, 2011.

[40] V. R. Wilson and J. N. Owens, "The reproductive biology of totara (Podocarpus totara) (Podocarpaceae)," Annals of Botany, vol. 83, no. 4, pp. 401-411, 1999.

[41] K. Rafińska and E. Bednarska, "Localisation pattern of homogalacturonan and arabinogalactan proteins in developing ovules of the gymnosperm plant Larix decidua Mill," Sexual Plant Reproduction, vol. 24, no. 1, pp. 75-87, 2011.

[42] J. J. Runions and J. N. Owens, "Sexual reproduction of interior spruce (Pinaceae). I. Pollen germination to archegonial maturation," International Journal of Plant Sciences, vol. 160, no. 4, pp. 631-640, 1999. 

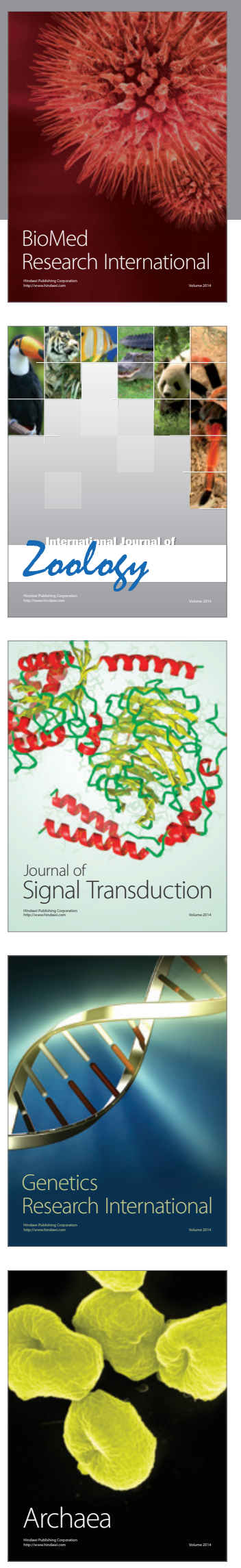
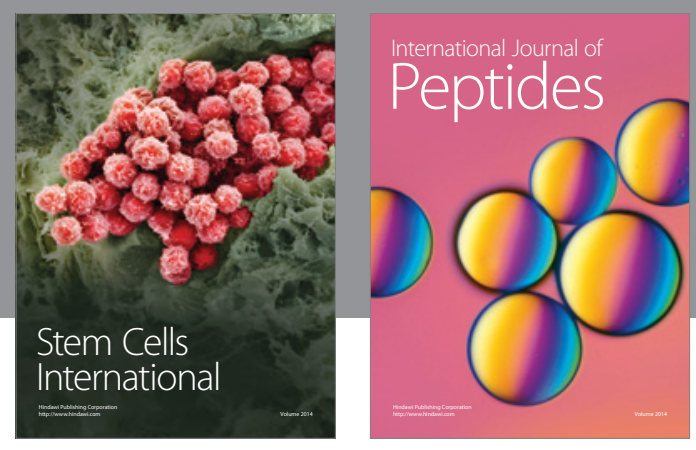

Submit your manuscripts at

http://www.hindawi.com
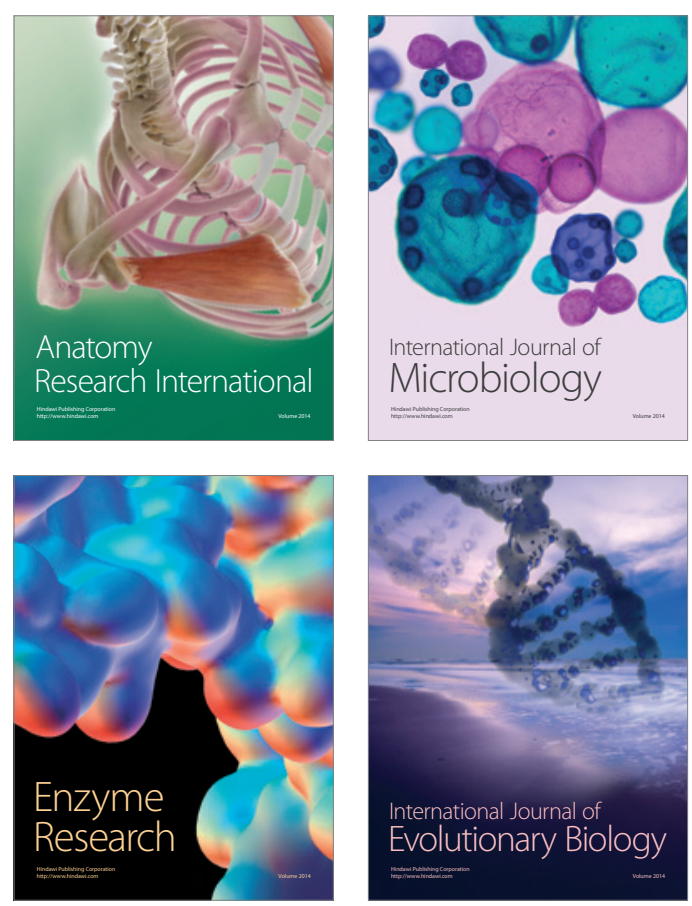
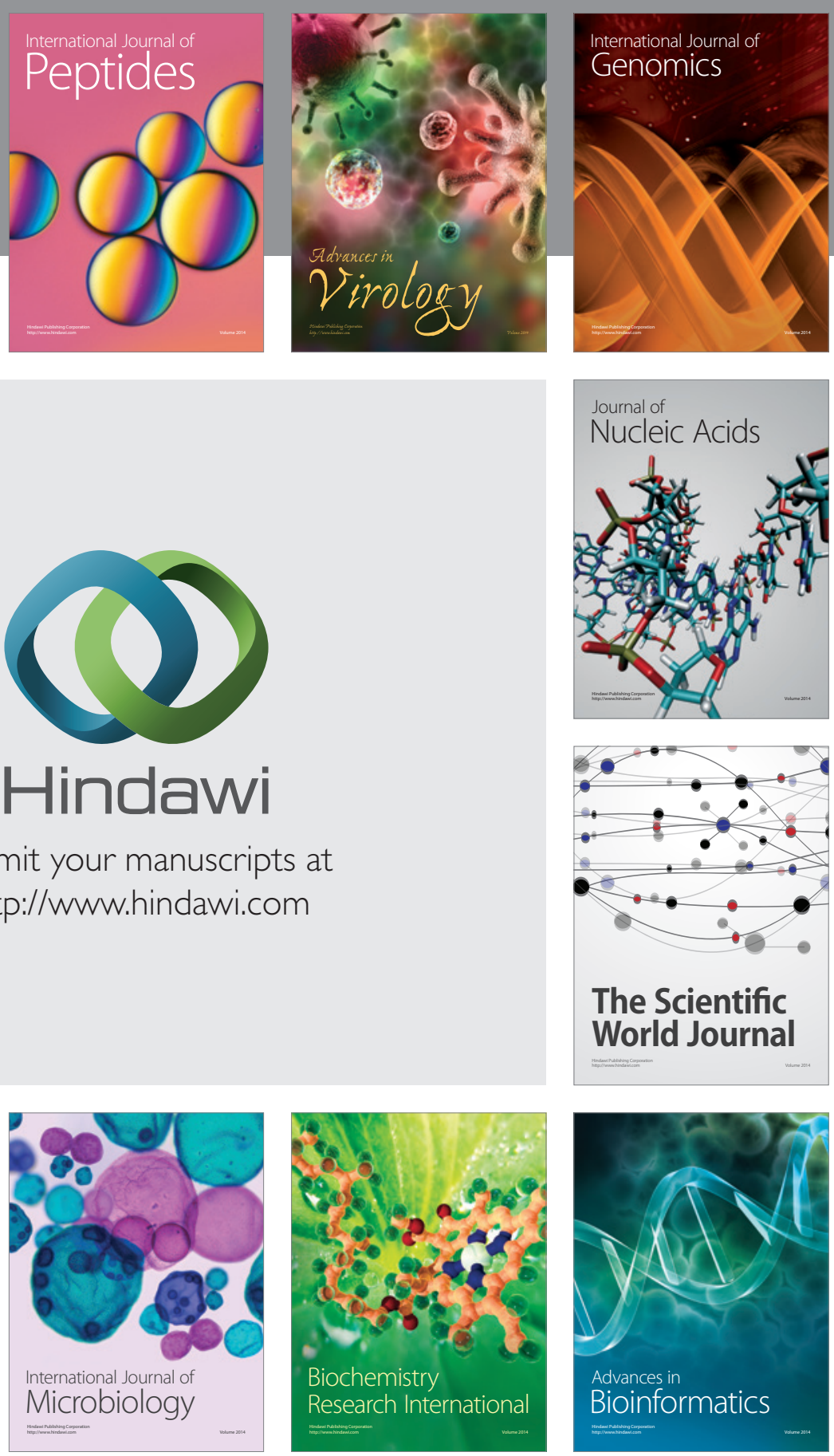

The Scientific World Journal
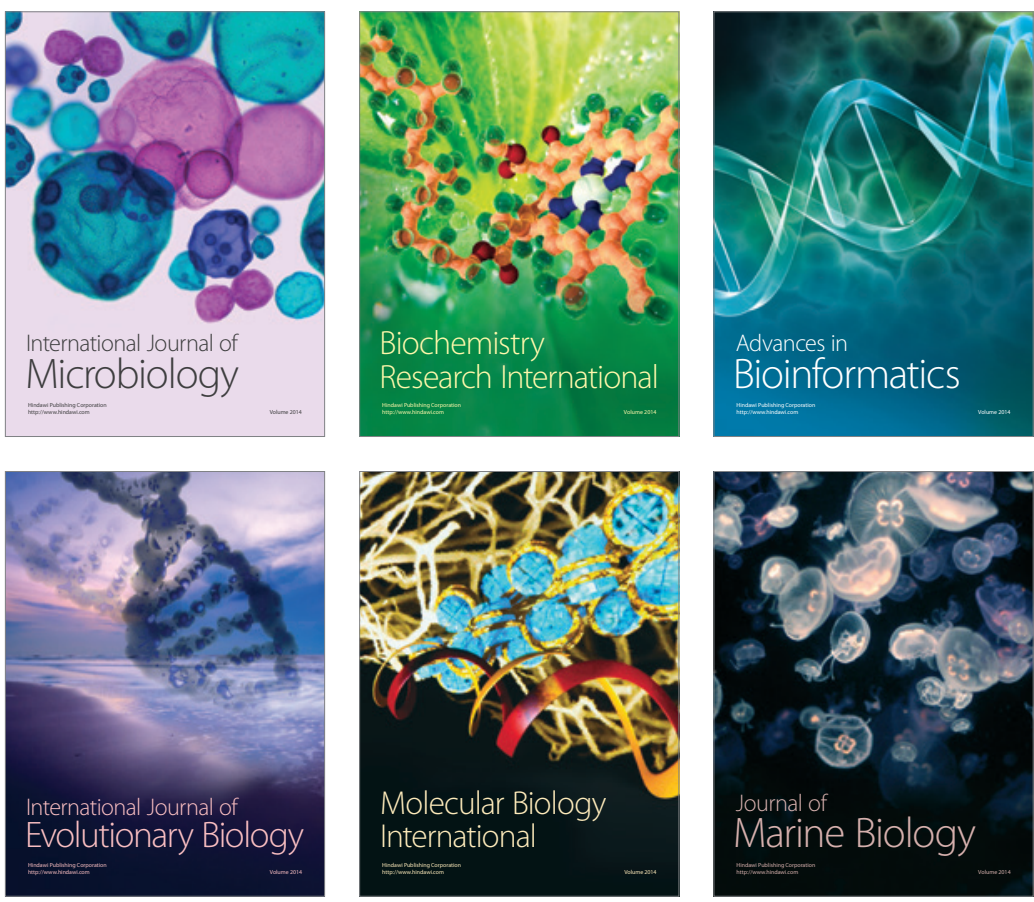